\title{
Efeito do Cádmio no fígado de girinos
}

\section{de rã-touro}

\begin{tabular}{|c|c|}
\hline $\begin{array}{l}\text { Felipe Lissoni de An- } \\
\text { drade Nogueira }\end{array}$ & $\begin{array}{l}\text { Programa de Pós-graduação em Biotecnologia e } \\
\text { Monitoramento Ambiental. Unidade de Sorocaba, } \\
\text { Universidade Federal de São Carlos, Sorocaba, } \\
\text { SP, Brasil }\end{array}$ \\
\hline & E-mail: felipe.lissoni@gmail.com \\
\hline \multirow[t]{2}{*}{$\begin{array}{l}\text { Fábio Camargo Abdalla } \\
\text { Monica Jones Costa } \\
\text { Raquel Fernanda Salla }\end{array}$} & $\begin{array}{l}\text { Laboratório de Biologia Estrutural e Funcional e } \\
\text { Laboratório de Fisiologia da Conservação. Unidade } \\
\text { de Sorocaba, Universidade Federal de São Carlos, } \\
\text { Sorocaba, SP, Brasil }\end{array}$ \\
\hline & $\begin{array}{r}\text { E-mail: fabdalla@ufscar.br, } \\
\text { monica@ufscar.br, } \\
\text { raquelsalla@hotmail.com }\end{array}$ \\
\hline
\end{tabular}

Recebido em: 9 jun. 2017. Aceito: 10 jul. 2017.

DOI: http://dx.doi.org/10.21674/2448-0479.32.447-471

\section{Resumo}

O cádmio está presente em todos os ambientes impactados pela ação antrópica e age de forma negativa sobre sistemas biológicos. Devido às suas propriedades tóxicas, o cádmio é um dos vários elementos que contribuem para o declínio de populações de anfíbios. Portanto, a ação do cádmio (Cd) durante o desenvolvimento pré-metamórfico em anfíbios, fígados de girinos de rã-touro, Lithobates catesbeianus, foi analisada através de microscopia de luz. Os

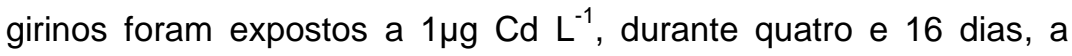
partir do estágio 25 de Gosner. Para as análises histoquímicas fo- 
ram utilizadas as técnicas PAS, Azul de Bromofenol e Azul da Prússia. A morfometria foi realizada pela contagem relativa da quantidade de células melanomacrofágicas. Os resultados mostraram aumento significativo das células melanomacrofágicas no grupo exposto a quatro dias, porém não aos 16 dias. A técnica de Azul da Prússia demonstrou intensa atividade de captação de ferro pelas células melanomacrofágicas dos indivíduos do grupo exposto durante quatro dias. Com relação aos hepatócitos, a técnica de PAS-Azul de Bromofenol indicou diminuição de glicoconjugados neutros e proteínas totais nos grupos expostos após quatro e 16 dias. O Cd impactou de forma mais drástica os girinos após quatro dias de exposição, indicando a rápida resposta adaptativa destes animais aos efeitos nocivos do metal-traço. Conclui-se que o cádmio afeta o fígado dos girinos em estágios iniciais do desenvolvimento, mesmo a concentrações permitidas pelo CONAMA (2005) para corpos d'água das classes I, II e IV.

Palavras-chave: Anuro. Biomarcadores. Ecotoxicologia. Hepatócitos. Metal-Traço.

\section{Abstract \\ Effect Of Cadmium On The Liver Of Bullfrog Tadpoles}

Chemical compounds metabolically active originated from intense industrialization can contribute to the worldwide decline of amphibian populations. Cadmium is a highly toxic compound, considered an endocrine disrupter. For the analysis of its toxicological effects, this study used the liver of pre-metamorphic (Gosner 25 stage) bullfrog tadpole, Lithobates catesbeianus. The study assessed the effect of 


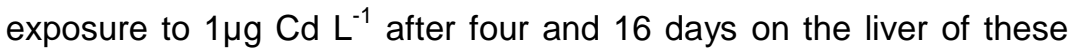
tadpoles through morphological and histochemical techniques. General morphological analysis was performed under routine microscopy, and for histochemical analyzes (PAS, Bromophenol Blue and Prussian Blue). Morphometry was performed by counting the relative amount of melano-macrophage cells. The morphometry showed significant increase in melano-macrophage cells in the hepatocytes exposed after four days, indicating sensitivity of the immune system to this xenobiotic. The Prussian Blue revealed intense activity the melano-macrophage cells of individuals exposed after four days due to the higher incidence of iron in these cells. Regarding the hepatocytes, the PAS-Blue Bromophenol technique showed a decrease of neutral glycol-conjugates and total protein in both exposed groups (four and 16 days). It can be concluded that cadmium affects the liver of tadpoles in the early stages of development of bullfrog tadpoles, even at concentrations allowed by CONAMA (2005) to Classes I, II and IV water bodies.

Keywords: Anura. Biomarkers. Ecotoxicology. Hepatocytes. Trace Metals.

\section{Introdução}

A rã-touro (Lithobates catesbeianus, Shaw, 1802) é um ranídeo naturalmente endêmico do leste da América do Norte (FROST, 2016). Possui porte avantajado e crescimento corpóreo contínuo ao longo de quase toda a sua vida. Apresenta hábitos alimentares generalistas e, como predadora, regula a ocorrência e demografia de populações sintrópicas em seu ambiente natural (CUNHA; DELARI- 
VA, 2009). Atualmente a espécie encontra-se distribuída pelo território brasileiro, tanto em produções comerciais como na natureza. Em relação ao ponto de vista experimental, $L$. catesbeianus é de fácil manutenção em cativeiro e para a experimentação animal (FRANÇA-SALGUEIRO, 2013). Assim, a rã-touro é utilizada como um modelo animal para experimentos toxicológicos, não só devido às suas características físicas (tamanho e resistência), como também por ser um anfíbio anuro modelo com vasta literatura científica e não ameaçado de extinção.

O tegumento dos Anura é um órgão importante para as trocas gasosas e deve ser mantido úmido. Assim, a evaporação da água pelo tegumento limita a atividade da maioria dos anfíbios a microambientes úmidos. Aproximadamente $70 \%$ das espécies de anfíbios anuros possuem ciclo de vida vinculado a ambientes aquáticos, fato que os torna bons indicadores da qualidade da água (FRANÇASALGUEIRO, 2013). Além disto, seus órgãos internos podem ser utilizados como biomarcadores morfológicos de efeito, com obtenção de resultados mais específicos sobre o impacto de xenobióticos na organofisiologia geral do organismo (ABDALLA et al., 2013; DALMEDICO et al., 2014; SALLA et al., 2016; RISSOLI et al., 2016).

O fígado é um bom exemplo de biomarcador de efeito (OLIVEIRA et al., 2016), pois é responsável pela síntese de muitas proteínas e enzimas relacionadas ao metabolismo geral, intermediário e secundário. Este órgão também é responsável pela desintoxicação e metabolização de toxicantes presentes no sangue, assim como pelas respostas inflamatórias, imunitárias humorais e celulares. Como em todos os vertebrados, o fígado é responsável pela biossíntese de estrogênio, testosterona, adrenalina e noradrenalina. Além destas funções, esse órgão é capaz de controlar a glicemia, acumulando glicose na forma de glicogênio, ou mobilizando o glicogênio, liberan- 
do glicose na corrente sanguínea (FORBES et al., 2006; GUYTON; HALL, 2006). O fígado é revestido por uma camada de tecido conjuntivo com projeções em direção ao interior do órgão. Estas estruturas recebem o nome de lobos e lóbulos hepáticos onde forma-se uma delicada rede de fibras reticulares que suporta os hepatócitos e células endoteliais dos capilares sinusóides (MARTINEZHERNANDEZ; AMENTA, 1995). A organização histológica geral do fígado de anfíbios em estágios iniciais do desenvolvimento prémetamórficos consiste de um parênquima em arranjo cordonal de hepatócitos (células funcionais do fígado) e um estroma de tecido conjuntivo, contendo sinusóides. No estroma encontram-se células especializadas na captação de ferro, devido a atividade fagocitária de eritrócitos senescentes, metabolização de hemoglobina, secreção de proteínas relacionadas com processos imunitários e fagocitose de bactérias que penetrem no sangue a partir do intestino (AGIUS, 1980; ZUASTI et al., 1990; CHRISTIANSEN et al., 1996; RUND et al., 1998). Essas células são designadas células melanomacrofágicas, as quais são homólogas às células de Küpffer de outros vertebrados.

Devido às características biológicas peculiares dos anfíbios, muitas populações estão desaparecendo e muitas espécies estão ameaçadas de extinção (FROST, 2016). Muitas são as causas para tal fenômeno, porém o aquecimento global, a agricultura intensiva, a industrialização e consequente destruição dos biomas e liberação de xenobióticos são as principais causas conhecidas para o fenômeno citado acima (BRÜHL et al., 2013).

Compostos químicos contendo cádmio são liberados no meio ambiente por meio de atividades industriais e de mineração, contaminando corpos d'água. Como todo metal-traço altamente catiônico, o cádmio interage com enzimas, causando a inibição de alguns sis- 
temas de absorção de nutrientes inorgânicos e orgânicos pelo organismo, ou mesmo competindo com enzimas associadas à neutralização de metais tóxicos, como é o caso das enzimas da família das metalotioneínas (CARDOSO; CHASIN, 2001; MINGULA et al., 2004; SETH et al., 2005; NOWIS et al., 2006). O cádmio é também um potente elemento mutagênico e carcinogênico, desregulador endócrino, promotor indireto do estresse oxidativo e desestabilização do citoesqueleto (WORLD..., 2011).

O Conselho Nacional do Meio Ambiente (CONAMA) é o órgão brasileiro responsável pelo estabelecimento de concentrações limites, consideradas ambientalmente seguras, de elementos potencialmente tóxicos na água. A concentração máxima de cádmio permitidas em águas doces das classes I, II e IV é de $1 \mu \mathrm{g} \mathrm{Cd} \mathrm{L}^{-1}$. Diversos são os efeitos da exposição de anfíbios ao cádmio. Dentre estes, pode-se destacar o atraso e/ou inibição da metamorfose e redução do crescimento em girinos (LOUMBOURDIS et al., 1999; FORT et al., 2000; FLAMENT et al., 2003;), mimetização de hormônios endógenos, estimulando/inibindo a síntese e metabolismo de hormônios ou modificando os níveis de receptores hormonais (MARTINS et al., 2012). Poligonadismo não funcional e reversão sexual durante 0 desenvolvimento gonadal também já foram descritos (ABDALLA et al., 2013). O cádmio compromete severamente o funcionamento e a fisiologia cardíaca, provocando um efeito cardiodepressor em rãstouro, alterando a fisiologia geral e consequentemente, demandando alto gasto energético na tentativa de manter a homeostase geral (DAL MEDICO et al., 2014). Assim, a intoxicação pelo cádmio pode afetar processos metabólicos, fazendo com que ocorra um desequilíbrio homeostático no organismo (SOUZA-SILVA, 2013) que, se a princípio pode não ser imediatamente letal, a médio e longo prazo pode reduzir o fitness de populações inteiras devido ao desvio ener- 
gético dos organismos dispendido para manter ou reestabelecer o equilíbrio homeostático.

Pelo anteriormente exposto, o objetivo do presente estudo foi de avaliar possíveis efeitos do cádmio em fígados de girinos de rãtouro expostos, a partir do estágio 25 de Gosner, por quatro e 16 dias a $1 \mu \mathrm{g} \mathrm{L}^{-1}$ deste metal-traço.

\section{Materiais e Métodos}

\section{Coleta do material e manutenção em laboratório}

O trabalho foi realizado nos Laboratórios de Biologia Estruturam e Funcional e de Fisiologia da Conservação, UFSCar - Campus de Sorocaba. Foram coletados duzentos girinos recém-eclodidos de rãs-touro, Lithobates catesbeianus (SHAW, 1802). No laboratório, os animais foram mantidos em aquários de $50 \mathrm{~L}$ com circulação contínua de água declorinada $(1,2 \mathrm{~L} / \mathrm{h})$, aeração constante, temperatura controlada $\left(25 \pm 1^{\circ} \mathrm{C}\right)$ e fotoperíodo natural ( $12 \mathrm{~h}$ claro: $12 \mathrm{~h}$ escuro) até atingirem o estágio 25 de Gosner (1960). Os animais foram alimentados ad libitum com ração comercial farelada para peixes Alcon Garden Basic Sticks ${ }^{\circledR}$ (composição: http://alconpet.com.br/produto/alcon-garden-basic-sticks até atingirem o estágio 25 de Gosner, 1960), isto é, o início da alimentação independente ( 10 dias). 


\section{Delineamento experimental para os ensaios ecotoxi- cológicos}

A água foi monitorada para garantir que os parâmetros físicoquímicos fossem mantidos dentro dos valores normativos segundo a American Society for Testing and Materials (2000). Tais valores $(\mathrm{pH}$ 7,1 - 7.3; dureza $\mathrm{CaCO}_{3} 28$ - $34 \mathrm{mg} \mathrm{L}{ }^{-1} ; \mathrm{DO}_{2} 6,8$ - 7,5 $\mathrm{mg} \mathrm{L}^{-1}$ ), são similares àqueles observados em grande parte das águas continentais do Brasil (CONSELHO..., 2005). Cada grupo experimental foi ensaiado em triplicata. No primeiro ensaio toxicológico (exposição subaguda de quatro dias), os anfíbios foram divididos em dois grupos experimentais, ensaiados em triplicata, e em sistema estático: grupo controle (CTR, $n=10$ ) e grupo exposto (EXP, $n=10$ ) a $1 \mu \mathrm{g}$ $\mathrm{Cd} \mathrm{L} \mathrm{L}^{-1}$, concentração correspondente ao valor máximo permitido para corpos d'água de classes I, II e IV pelo CONAMA - Resolução № 401/2005.

Após a exposição, os animais do grupo controle e do grupo exposto foram eutanasiados por concussão cefálica de acordo com os princípios propostos pela American Veterinary Society e aprovação do Comitê de Ética da UFSCar (protocolo número. 034/2012 http://www.propq.ufscar.br/comissoes-de-etica/comissao-de-eticanaexperimentacaoanimal). Os fígados foram retirados e depois transferidos para o fixador paraformaldeído tamponado (paraformaldeído $4 \%$ em tampão fosfato, $0,1 \mathrm{M}, \mathrm{pH} 7,24)$ para histoquímica. Para o segundo ensaio experimental (exposição subaguda de 16 dias), foram realizados os mesmos procedimentos descritos anteriormente. Foi realizada também a renovação da água nos aquários a cada quatro dias. 


\section{Preparação do material para análise morfológica}

Os fígados dos girinos foram dissecados em fragmentos de no máximo $3 \mathrm{~mm}$ de espessura e fixados em paraformaldeído tamponado (paraformaldeído $4 \%$ em tampão fosfato, $0,1 \mathrm{M}, \mathrm{pH} 7,2$ ) e desidratados em concentrações crescentes de álcool (15\%, 30\%, 50\%, $70 \%, 80 \%, 90 \%$ e $95 \%$ ) a temperatura de $4^{\circ} \mathrm{C}$. Em seguida, o material foi submetido a dois banhos em álcool PA e a um banho em solução de álcool PA e xilol PA (1:1) e diafanizados em xilol. Em seguida o material foi incluído em historesina (JB-4, Leica Polysciences, Germany), desta forma, cortes histológicos de 1,5 $\mu \mathrm{m}$ de espessura foram realizados em micrótomo Leica® RM225. Após, preparadas 10 lâminas de cada indivíduo, onde cada lâmina continha 12 cortes com diferentes profundidades e contemplando diferentes regiões do fígado. As lâminas foram coradas com hematoxilina e eosina seguindo protocolos de rotina para as análises morfológicas e morfométricas. As lâminas foram analisadas em microscópio Leica - DM1000, por meio do programa Leica Application Suite V3.8 (LASV3.8).

\section{Técnicas histológicas histoquímicas}

Para as análises histoquímicas foram utilizadas as técnicas: PAS conjugada ao Azul de Bromofenol para detecção de glicoconjugados neutros e proteínas totais, respectivamente, e Azul da Prússia (detecção de ferro) de acordo com Pearse (1960). As lâminas foram analisadas em mesmo equipamento descrito no item 2.3.

\section{Tratamento estatístico dos dados}

O tratamento estatístico dos dados foi realizado a partir da contagem de células melanomacrofágicas de 10 lâminas diferentes de 
cada indivíduo, ou seja, 10 controles e 10 expostos, totalizando 120 medições (seções histológicas) por indivíduo e 1.200 por grupo (controle ou expostos). Os resultados foram analisados estatisticamente através de análise estatística descritiva (média e desvio padrão) e análise de variância multifatorial não paramétrica, teste Tukey e Scheffé (ANOVA), com grau de confiança de 0,05\%, através do software GraphPad Prism 5. Os resultados dos dados estatísticos de variância multifatorial foram representados em gráfico de colunas.

\section{Resultados e Discussão}

\section{Análise morfológica geral}

\section{Quatro Dias de Exposição ao Cádmio}

Estudos realizados com rã-touro demonstram que o cádmio é capaz de afetar diversas funções biológicas destes animais, como alterações na função cardíaca (DAL MEDICO et al., 2014); teratogênese da pele, olhos e sistema digestório (SUNDERMAN et al.,1991). Nos fígados de indivíduos expostos a quatro dias observou-se aumento da incidência de células melanomacrofágicas que se agruparam, formando agregados de células, ou centros melanomacrofágicos, nos grupos expostos (Figs. 1B, D), indicando que agentes estressores, neste caso o cádmio, podem estimular o sistema imunitário dos girinos através das células melanomagrofágicas. Além da agregação das células melanomacrofágicas no estroma hepático, observou-se que os hepatócitos foram severamente afetados pelo cádmio, apresentando citoplasma vacuolizado, menos basófilo e com núcleo picnótico, indicando morte celular (Figs. 1C,D). 
Uma das características marcantes do efeito da toxidade do cádmio, tanto em vertebrados com em invertebrados, é sua capacidade de provocar fragmentação cromatínica, picnose nuclear e vacuolização do citoplasma (ABDALLA et al., 2013; ABDALLA E DOMINGUES, 2015). Geralmente a concentrações baixas, o cádmio provoca morte celular e a concentrações consideradas altas, necrose. Em todos os casos há ocorrência de autofagia (TEMPLETON; LIU, 2010).

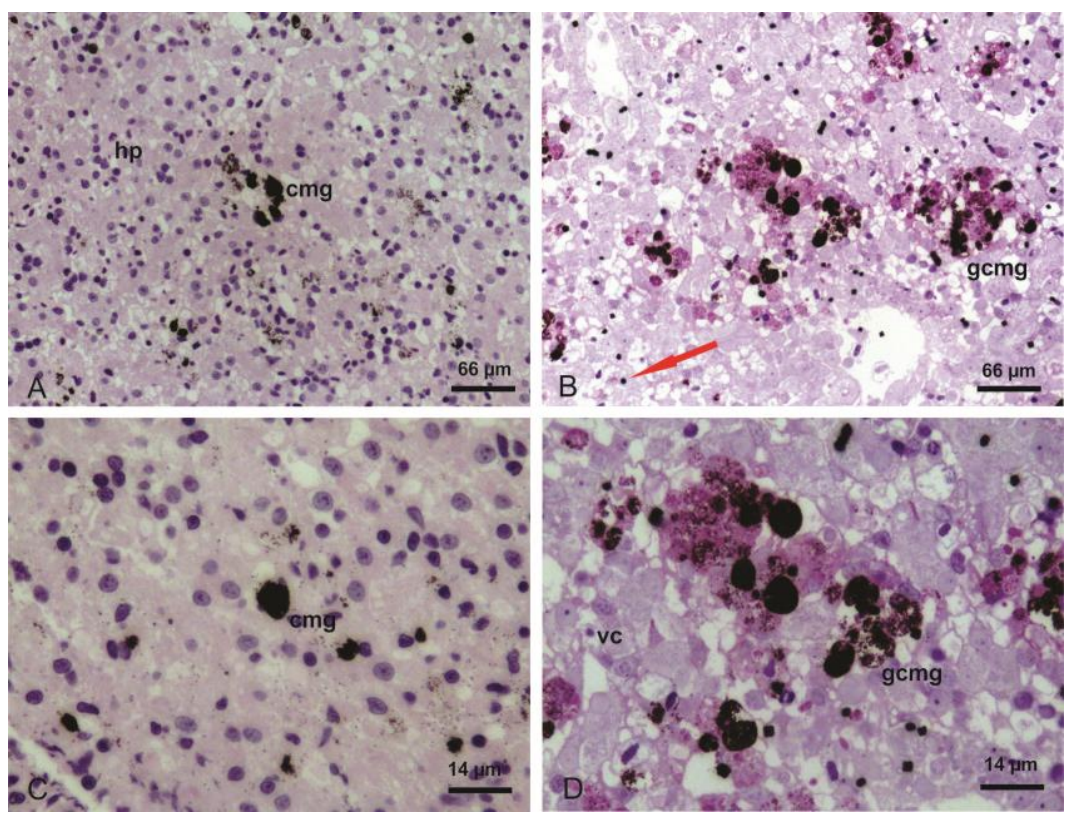

Figura 1. HE - Quatro dias de Exposição ao Cádmio. (A) Hepatócitos (hp) e célula melanomacrofágica (cmg) do grupo controle. (B) Grupo exposto, agregados de células melanomacrofáficas $(\mathrm{gcmg})$ e núcleo picnótico de hepatócito indicados pela seta. (C) Grupo Controle, célula melanomacrofágica (cmg). (D) Grupo exposto, vacuolização citoplasmática dos hepatócitos (vc) e agregado de células melanomacrofágicas (gcmg). 


\section{Dezesseis Dias de Exposição ao Cádmio}

Diversos estudos relatam efeitos de xenobióticos sobre a morfologia e a fisiologia de anfíbios (DAL MEDICO et al., 2014; RISSOLI et al., 2016; SALLA et al., 2016), característica observada também por meio da exposição por 16 dias ao cádmio, em que a incidência de agregados de células melanomacrofágicas foi maior no grupo exposto do que no controle (Figs. 2A-D). Verificou-se também picnose nuclear nos hepatócitos (Fig. 2B). Através das análises morfológicas, observou-se um aumento de eritrócitos e leucócitos nos capilares sinusóides (Fig. 2B).

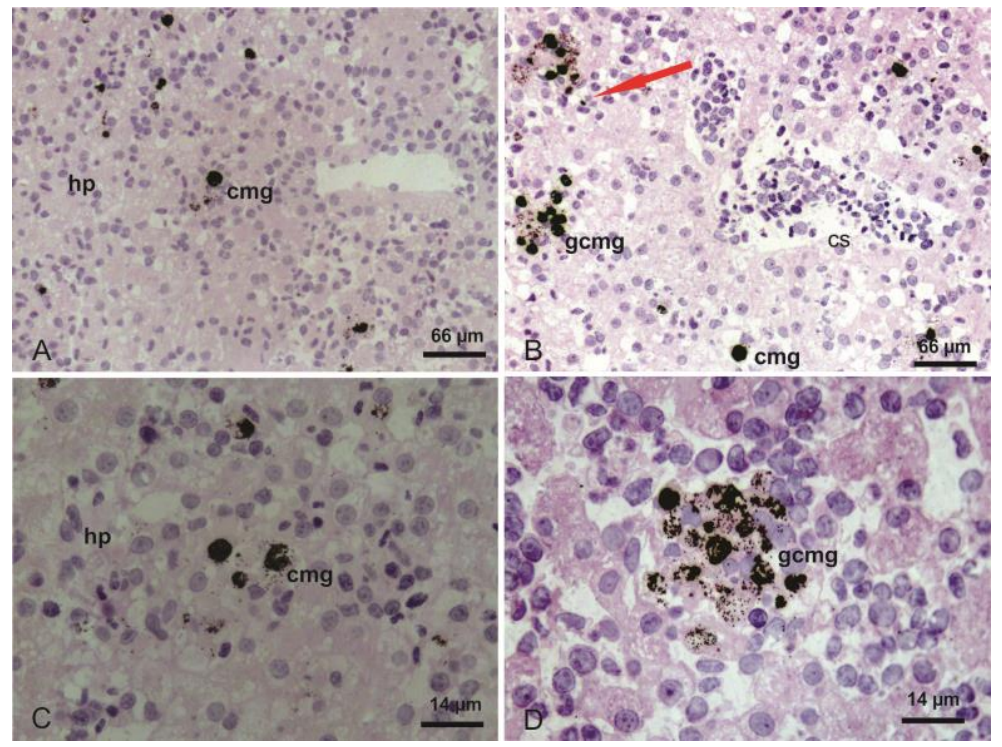

Figura 2. HE - 16 Dias de Exposição ao Cádmio. (A) e (C) Hepatócitos (hp) e células melanomacrofágicas (cmg) do grupo controle. (B) Agregados de células melanomacrofágicas (gcmg), núcleos picnóticos indicado pela seta e capilares sinusóides (cs). (D) Agregado de células melanomacrofágicas ( $\mathrm{gcmg}$ ). 
Com relação ao tipo e intensidade das respostas celulares e humorais que cádmio provoca, os dados da literatura são controversos, havendo pesquisas que não relatam qualquer alteração nas mesmas, enquanto outras descrevem seu aumento ou diminuição. Vale ressaltar que tais variações na incidência e tipo de morte celular, as respostas imunitárias parecem depender da concentração do agente estressor, do organismo e do tempo de exposição ao cádmio (Abdalla comunicação pessoal).

\section{Análise histoquímica}

\section{PAS e Azul de Bromofenol}

\section{Quatro Dias de Exposição ao Cádmio}

Observou-se uma nítida diferença dos hepatócitos em relação à presença de glicoconjugados neutros e proteínas do grupo exposto em relação ao grupo controle. Dessa forma, as imagens do grupo controle (Figs. 3A e 3C) apresentaram um predomínio muito maior destas moléculas, em relação ao grupo exposto (Figs. 3B e 3D).

Os resultados sugerem que os hepatócitos dos indivíduos do grupo exposto estavam em intensa atividade metabólica, desempenhando suas funções como principal órgão do metabolismo secundário, utilizando os glicoconjugados e proteínas como suprimento energético e enzimático para as atividades relacionadas às funções do fígado. Os resultados indicam que houve maior mobilização glicoconjuados (rosa) do que de proteínas (azul) nos animais expostos (Figs. 4C e 4D). Tal mobilização de glicoconjugados, provavelmente glicogênio, pode estar associada a uma maior demanda energética 
frente a uma resposta de defesa fisiológica dos grupos expostos

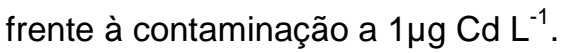
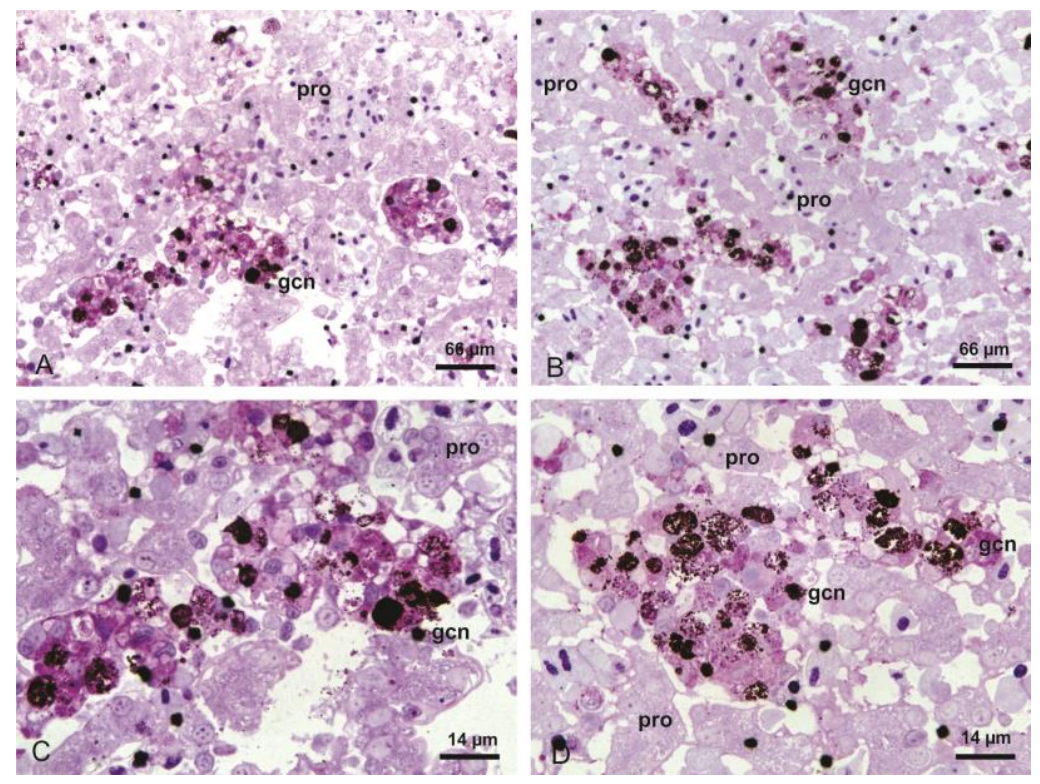

Figura 3. PAS-Azul de Bromofenol - 4 Dias de Exposição ao Cádmio: (A) e (C) Grupo controle, grande incidência de proteínas (pro) e grânulos de glicoconjugados neutros (gcn) nas células melanomacrofágicas. (B) e (D) Predomínio maior de proteínas (pro), evidenciado pelo tecido mais azulado do que do grupo controle e menor granulação de glicoconjugados neutros ( $\mathrm{gcn}$ ) tanto nos hepatócitos (rosa mais claro) como na formação de grânulos nos hepatócitos do grupo exposto.

\section{Dezesseis Dias de Exposição ao Cádmio}

Os indivíduos expostos a 16 dias continuaram apresentando o mesmo padrão observado nos indivíduos expostos durante quatro dias ao cádmio, porém com evidências mais intensas de mobilização das macromoléculas estudadas (Figs. 4A-D). Houve maior consumo do suprimento de glicogênio e proteínas pelos hepatócitos, 
possivelmente para suprir as necessidades energéticas dos hepatócitos de forma mais intensa em relação aos indivíduos submetidos apenas a quatro dias de exposição. 16 Dias de Exposição ao Cádmio
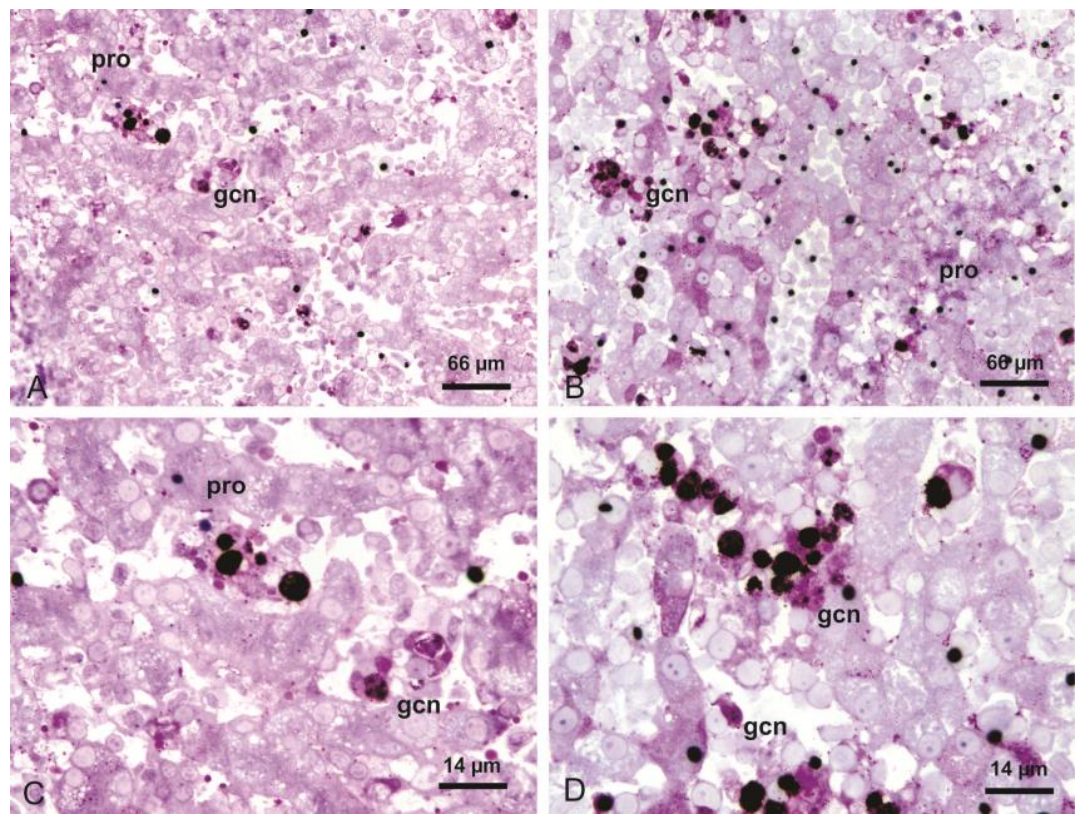

Figura 4. PAS - Azul de Bromofenol - 16 Dias de Exposição ao Cádmio. (A) e (C) Grupo controle, grande incidência de proteínas (pro) e glicoconjugados neutros (gcn).

(B) Coloração azulada devido a mobilização de glicogênio entre as células, menor predominância de proteínas (pro) e glicoconjugados neutros (gcn). (D) Grupo exposto evidenciando escassa reserva de glicoconjudos neutros (gcn) e proteínas totais.

\section{Azul da Prússia}

\section{Quatro Dias de Exposição ao Cádmio}

Os indivíduos expostos a quatro dias apresentaram células melanomacrofágicas em intensa atividade provavelmente devido à fagocitose de eritrócitos afetados pelo cádmio. Com relação ao grupo 
controle (Figs. 5A,B) observou-se intensa atividade das células melanomacrofágicas das células do grupo exposto (Figs. 5C,D), através da maior pigmentação azul situada nas células e nos agregados de células melanomacrofágicas, as quais, à semelhança de outros vertebrados, possui função de fagocitar de eritrócitos senescentes ou danificados e metabolizar o ferro dos grupo heme desses eritrócitos para posterior reutilização no processo eritropoético (HIPOLITO et al, 2004).

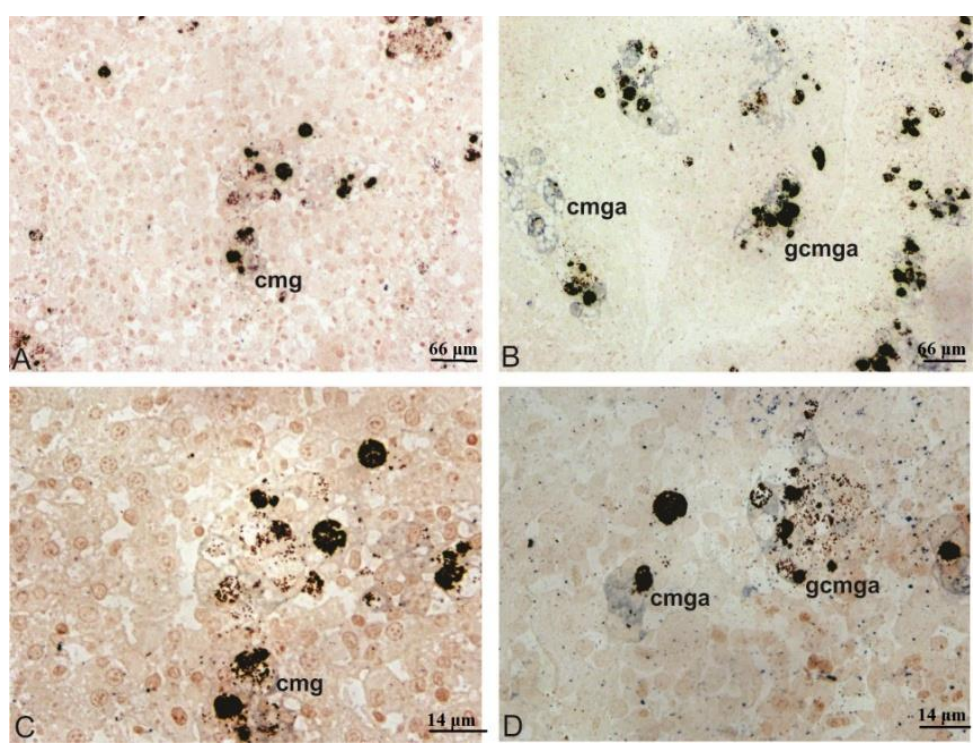

Figura 5. Azul da Prússia - 4 Dias de Exposição ao Cádmio. (A) e (C) Grupo controle, atividade basal das células melanomacrofágicas (cmg). (B) e (D) Grupo exposto, células melanomacrofágicas ativas (cmga) e agregados de células melanomacrofágicas ativas (cmga) e agregados de células melanomacrofágicas ativas ( $\mathrm{gcmga}$ ) evidenciado pela intensa coloração azul. 


\section{Dezesseis Dias de Exposição ao Cádmio}

Os indivíduos expostos por 16 dias ao cádmio mostram atividade basal das células melanomacrofágicas tanto no grupo controle como no grupo exposto (Figs. 6A-D). Os resultados demonstraram que a as células melanomacrofágicas do grupo exposto (Figs. 6B,D) apresentam maior incidência de agregados de células melanomagrofágicas. No entanto, a quantidade de ferro detectada pela técnica histoquímica não destoa da do grupo controle, como observado nos girinos expostos por quatro dias.

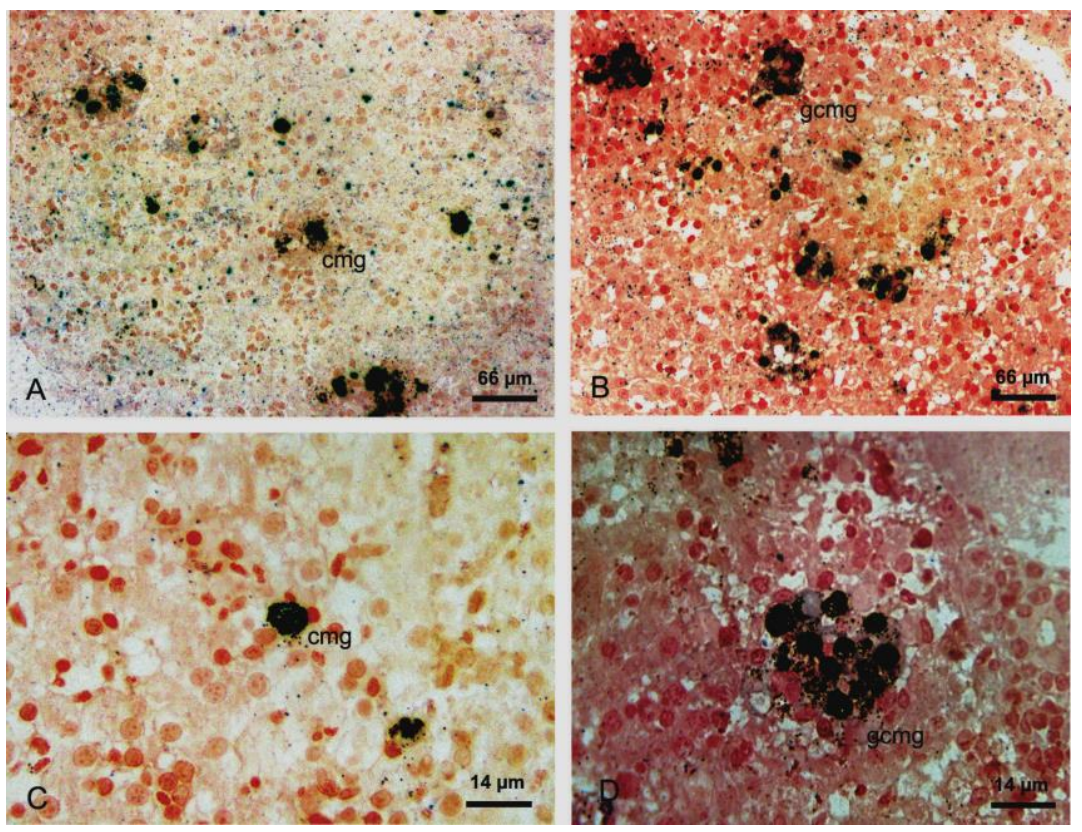

Figura 6. Azul da Prússia - 16 Dias de Exposição ao Cádmio. (A e C) Grupo controle, atividade fagocitária basal das células melanomacrofágicas $(\mathrm{cmg})$ evidenciada pela ausência ou fraca pigmentação azul (B e D). Grupo exposto, agregados de células melanomacrofágicas (gcmg) em atividade basal. 


\section{Análise quantitativa}

Os indivíduos expostos a quatro dias diferiram significativamente do seu respectivo controle, bem como dos grupos controle e expostos por 16 dias no que se refere ao número de células melanomacrofágicas, as quais quase triplicaram com relação ao grupo controle de quatro dias (Fig. 7). Não houve diferença da quantidade de células melanomacrofágicas entre os grupos controle e exposto a 16 dias (Fig. 7).

Análise Quantitativa

Os resultados demonstraram que o cádmio contribuiu para o aumento de células melanomacrofágicas somente nos indivíduos expostos a quatro dias. Indivíduos expostos a 16 dias apresentaram número de células melanomacrofágicas estatisticamente igual ao do controle de quatro dias, portanto não houve aumento. $\mathrm{O}$ aumento da frequência de células melanomacrofágicas no grupo exposto a quatro dias provavelmente indica uma resposta à uma condição inflamatória devido à alta toxidade do cádmio.

Pelo o exposto, a função hepática da espécie analisada parece apresentar respostas compensatórias com relação ao cádmio, fato observado para outros toxicantes nesta espécie de vertebrado (OLIVEIRA et al., 2016), como em outras (COSTA et al., 2013), haja visto o maior impacto deste metal e, consequente maior resposta hepática, nos indivíduos expostos por 4 dias de idade. O quanto tal mecanismo compensatório demanda e desvia energia para mantê-lo não podemos inferir através dos resultados aqui apresentados, todavia toda compensação e desvio energético, ainda mais nesta fase importante do desenvolvimento dos anfíbios, pode ser determinante 
para o sucesso ou insucesso do indivíduo ou das populações expostas ao cádmio.

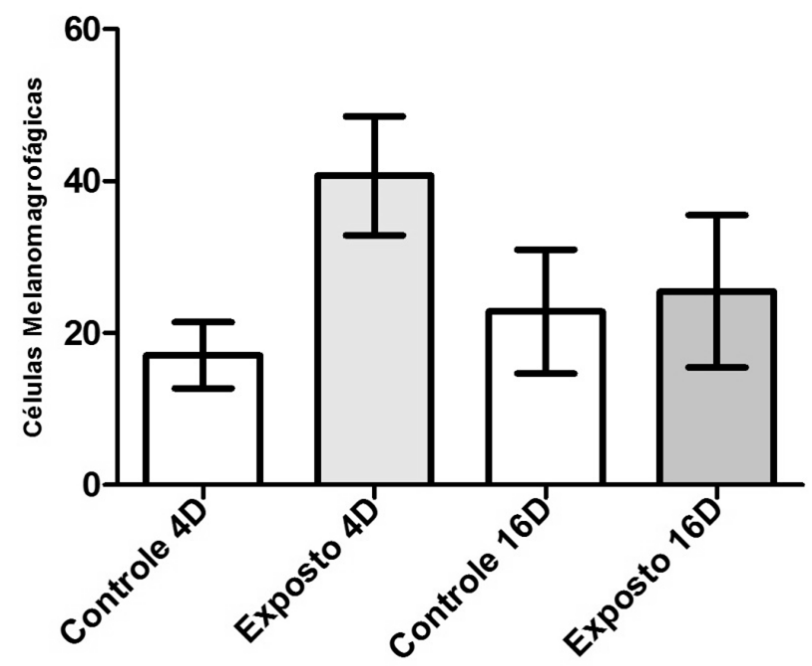

Figura 7. Número Relativo de Células Melanomacrofágicas entre os grupos controle e expostos a quatro (4D) e 16 (16D) dias. Quantidade significativa de células melanomacrofácas observadas somente nos indivíduos expostos a quatro dias (cinza claro). Não houve diferença da quantidade de células melanomacrofágicas entre os grupos controle e exposto a 16 dias (cinza escuro). Teste de Tukey, $p>0,05$.

\section{Conclusão}

Considerando-se que a concentração de cádmio utilizada no presente trabalho $\left(1 \mu \mathrm{g} \mathrm{Cd} \mathrm{L}^{-1}\right)$ corresponde àquela estabelecida pelo CONAMA (2005) como ambientalmente segura para este metaltraço para as águas das classes I, II e IV, os resultados deste estudo 
demonstraram claramente que esta concentração exerce um efeito deletério sobre as células do fígado de girinos após quatro e 16 dias de exposição a este metal-traço.

Ficou evidente que esta espécie é afetada severamente após quatro dias de exposição, aumentando o número de células melanomacrofágicas, mobilizando glicoconjugados e proteínas dos hepatócitos na tentativa de manter a homeostase. Verificou-se também aumento da incidência de eritrócitos nos capilares sanguíneos, o que está coerente com a constatação da maior atividade das células melanomacrofágicas na captação de ferro. Porções do fígado, neste período de exposição, mostraram os cordões hepáticos repletos de hepatócitos em morte celular, evidenciada pelos seus núcleos picnóticos. Entre o período de quatro a 16 dias, ou seja, em 12 dias após patente inflamação hepática, os girinos não mais apresentaram respostas à exposição ao cádmio, ou seja, os centros melanomacrofágicos diminuíram e não aparentaram mais atividade intensa na captação de ferro dos eritrócitos. A mobilização de macromoléculas nos hepatócitos continuou, assim como a alta incidência de morte celular. Pelo o exposto, para esta espécie e no contexto experimental desta pesquisa, os parâmetros estabelecidos como seguros pelo CONAMA (2005) no que concerne à concentração de cádmio permitida para águas doces onde estes animais são encontrados naturalmente não condizem com os dados da presente pesquisa, o que pode representar um risco adicional às populações de anfíbios devendo, portanto, ser revisadas. 


\section{Referências}

ABDALLA, F.C.; DOMINGUES, C.E.C. Hepato-Nephrocitic System: A Novel Model of Biomarkers for Analysis of the Ecology of Stress in Environmental Biomonitoring. Plos One, EUA, v. 10, n. 7, p. 1-9, jul. 2015.

ABDALLA, F.C. et al. The impact of cadmium chloride on the gonadal morphology of the North American bullfrog tadpoles, Lithobates catesbeianus (Shaw, 1802). Fresenius Environmental Bulletin, Grécia, v. 22, n. 7A, SI, p. 1962-1966, 2013.

AGIUS, C. Phylogenetic development of melano-macrophage centres in fish. Journal of Zoology of London. London, v. 191, n. 1, p. 11-31, may. 1980.

AMERICAN SOCIETY FOR TESTING AND MATERIALS - ASTM. Standard guide for conducting acute toxicity tests on test materials with fishes, macroinvertebrates, and amphibians. E 729-96 In: Annual Book of Standards, 1ed. Philadelphia: 2000. p. 220- 240.

BRÜHL, C. A. et al. Terrestrial pesticide exposure of amphibians: an underestimated cause of global decline? Scientific Reports, Landau, v. 3, n. 1. p. 1135, jan. 2013.

CARDOSO, L.M.N.; CHASIN, A.A.M. Ecotoxicologia do Cádmio e Seus Compostos. Bahia: Série Caderno de Referencia Ambiental, 2001.

CHRISTIANSEN, J.L.; GRZYBOWSKI, J.M.; KODAMA, R.M. Melanomacrophage aggregations and their age relationships in the yellow mud turtle, Kinosternon flavescens (Kinosternidae). Pigment Cell \& Melanoma Research, lowa, v. 9, n. 4, p. 185 - 190, aug. 1996. 
CONSELHO NACIONAL DO MEIO AMBIENTE (Brasil) - CONAMA. Resolução no 357 de 17 de março de 2005. Dispõe sobre a classificação dos corpos de água e diretrizes ambientais para o seu enquadramento. Disponível em: <http://www.mma.gov.br/port/conama/res/res05/res35705.pdf.> Acesso em: 03 jun. 2016.

CUNHA, E.R.; DELARIVA, R.L. Introdução da rã-touro, Lithobates catesbeianus (Shaw,1802): Uma revisão. SaBios: Revista de Saúde e Biologia, Maringá, v. 4, n. 2, p. 34-46, jul./dez. 2009.

DAL- MEDICO, S.E. et al. Negative Impact of a Cadmium Consentration Considered Environmentally Safe in Brazil (1 ppb) On The Cardiac Performace of Bullfrog tadpoles. Ecotoxicology and Environmental Safety, São Paulo, v.1, n. 104, p. 168-174, jun. 2014.

FLAMENT, S. et al. Effect of cadmium on gonadogenesis and metamorphosis in Pleurodeles waltl (Urodele Amphibian). Aquatic Toxicology, Amsterdam, v. 64, n. 2, p. 143-153, jul. 2003.

FORBES, V.E.F.; PALMQVIST, A.; BACH, L. The use and misuse of biomarkers in ecotoxicology. Environmental Toxicology and Chemistry, Roskilde, v. 25, n. 1, p. 272-280, apr./jun. 2006.

FORT, D.J. et al. Preliminary validation of a short-term morphological assay to evaluate adverse effects on amphibian metamorphosis and thyroid function using Xenopus laevis. Journal of Applied Toxicology, Oklahoma, v. 20, n. 5, p. 419-425, sep./oct. 2000.

FRANÇA-SALGUEIRO, F.M. Avaliação da Toxicidade de Agrotoxicos Utilizados na cultura de Arroz Irrigados para Girinos de 
Lithobates catesbeianus. 2013. Dissertação (Dotourado em Biotecnologia Industrial na Área de Conversão de Biomassa) - Escola de Engenharia de Lorena, Universidade de São Paulo, Lorena, 2013.

FROST, D.R. Amphibian Species of the World. American Museum of Natural History. New York. 2016. Disponível em: <http://research.amnh.org/vz/herpetology/amphibia/index.html.> Acesso em: 26 out. 2016.

GUYTON, A.C.; HALL, J.E. Tratado de Fisiologia Médica. Philadelphia: Elsevier Editora, 2006.

HIPOLITO, M.; MARTINS, A. M. C. R. P. F.; BACH, E. E. Aspectos bioquímicos em fígado de rã-touro (Rana catesbeiana Shaw, 1802) sadias e doentes. Arquivos do Instituto Biológico, v. 71, n. 2, p. 147-153, abr./jun. 2004.

LOUMBOURDIS, N.S.; KYRIAKOPOULOU-SKLAVOUNOU, P.; ZACHARIADIS, G. Effects of Cadmium Exposure On Bioaccumulation And Larval Growth In The Frog Rana ridibunda. Environmental Pollution, Thessaloniki, v. 104, n. 3, p. 429-433, mar. 1999.

MARTINEZ-HERNANDEZ, A.; AMENTA, P.S. The Extracellular Matrix In Hepatic Regeneration. The FASEB Journal, Tennessee, v. 9, n. 14, p. 1401-1410, nov. 1995.

MARTINS, A.M.C.R.P.F. et al. Disruptores Endócrinos: A Ameaça Insidiosa. Secretaria de Agricultura e Abastecimento Instituto Biológico (IB). $2012 . \quad$ Disponível em: <http://www.biologico.sp.gov.br/artigos_ok.php?id_artigo=177.> Acesso em: 26 out. 2016. 
MINGULA, P. et al. Antioxidative defence enzymes in beetles from a metal pollution gradient. Biologia Bratislava, Katowice, v. 59, n. 5, p. 645-654, jul. 2004.

NOWIS, D. et al. Heme oxygenase-1 protects tumor cells against photodynamic therapy-mediated cytotoxicity. Oncogene, Warsaw, v. 25, n. 24, p. 3365-3374, jun. 2006.

OLIVEIRA, C.R. et al. Hepatic effects of the clomazone herbicide in both its free form and associated with chitosan-alginate nanoparticles in bullfrog tadpoles. Chemosphere (Oxford), v. 149, p. 304-313, 2016.

PEARSE, A.G.E. Histochemistry, theoretical and applied. London: University London, 1960.

RISSOLI, R.Z. et al. Effects of glyphosate and the glyphosate based herbicides Roundup Original and Roundup Transorb on respiratory morphophysiology of bullfrog tadpoles. Chemosphere, São Carlos, v. 1, n. 156, p. 37-44, apr. 2016.

RUND, C.R.; CHRISTIANSEN, J.L.; JOHNSON, J.C. In vitro culture of melanomacrophages from spleen and liver of turtles: comments on melanomacrophage morphology. Pigment Cell Research, Des Moines, v. 11, n. 2, p. 114-119, apr. 1998.

SALLA, R.F. et al. Impact of an environmental relevant concentration of $17 \alpha$-ethinylestradiol on the cardiac function of bullfrog tadpoles. Chemosphere, Sorocaba, v. 1, n. 144, p. 1862-1868, oct. 2016. 
SETH, R.B.; EA, C.; CHEN, Z.J. Identification and Characterization of MAVS, a Mitochondrial Antiviral Signaling Protein that Activates NF-KB and IRF3. Cell, Dallas, v. 122, n. 9, p. 669-682, sep. 2005.

SOUZA-SILVA, R. Influência da Atividade de Garimpo na Bacia do Rio Cassiporé, Estado do Amapá, sobre o Estresse Oxidativo em Peixes. 2013. Dissertação (Mestrado em Biodiversidade Tropical) - Programa de Pós-Graduação em Biodiversidade Tropical, Universidade Federal do Amapá, Amapá, 2013.

SUNDERMAN, J.R.F.W.; PLOWMAN, M.C.; HOPFER, S.M. Embryotoxicity and Teratogenicity of Cadmium chloridein Xenopus laevis, Assayed by the FETAX Procedure. Annals of Clinical and Laboratory Science, Farmington, v. 21, n. 6, p. 381-391, nov. 1991.

TEMPLETON, D.M.; LIU, Y. Multiple roles of cadmium in cell death and survival. Chemico Biological Interactions, Toronto, v. 188, n. 2, p. 267-275, nov. 2010.

WORLD HEALTH ORGANIZATION - WHO. Cadmium in Drinkingwater Background document for development of WHO Guidelines for Drinking-water Quality. WHO/SDE/WSH/03.04/80/Rev/1, 2011 Geneva, Switzerland. Disponível em: < http://www.who.int/water_sanitation_health/dwq/chemicals/cadmium. pdf>. Acesso em: 05 jun. 2016.

ZUASTI, A. et al. Distribution of extracutaneous melanin pigment in Sparus auratus, Mugil cephalus, and Dicentrarchus labrax (Pisces, Teleostei). Pigment Cell Research, Copenhagen, v. 3, n. 3, p. 126131, sep. 1990. 